\title{
EXCLUSIVE DEALING AND COMMON AGENCY IN INTERNATIONAL MARKETS
}

\author{
HORST RAFF \\ NICOLAS SCHMITT \\ CESIFO WORKING PAPER NO. 1168 \\ CATEgory 7: TRADE Policy \\ APRIL 2004
}
An electronic version of the paper may be downloaded
- from the SSRN website:
- from the CESifo website:
www.SSRN.com
www. CESifo.de




\title{
EXCLUSIVE DEALING AND COMMON AGENCY IN INTERNATIONAL MARKETS
}

\begin{abstract}
This paper investigates the contractual choice between exclusive dealing and common agency in a simple international oligopoly model where products are sold through intermediaries. We find that when trade barriers are high domestic firms tend to adopt exclusive dealing contracts, whereas trade liberalization may lead firms to choose common agency. Irrespective of the level of trade barriers, the equilibrium contract adopted by each manufacturer is shown to decrease domestic welfare as compared to the other possible contract when products are close substitutes.
\end{abstract}

JEL classification: F12, F13, F15, L42.

\author{
Horst Raff \\ Christian-Albrechts-University at Kiel \\ Department of Economics \\ 24098 Kiel \\ Germany \\ raff@econ-theory.uni-kiel.de
}

\author{
Nicolas Schmitt \\ University of Geneva \\ Department of Economics and Politics \\ 1211 Geneva 4 \\ Switzerland \\ schmitt@ecopo.unige.ch
}

We thank Eric Bond, Antoine Soubeyran and seminar participants for useful comments on an earlier draft. Both authors acknowledge financial support from the Social Sciences and Humanities Research Council of Canada and from the Alexander-von-Humboldt Foundation. 


\section{Introduction}

This paper examines the contractual relations between manufacturers and intermediaries and their effects on international trade. Specifically, we investigate the contention that some contracts between manufacturers and distributors represent an important obstacle to international trade [see, for instance, OECD (1999), U.S. Department of Justice (2000)].

Exclusive dealing (ED) contracts, by which distributors agree not to carry brands from competing manufacturers, have attracted particular attention. For instance, ED has been at the heart of several trade disputes between the United States and Japan [Nagaoka and Goto (1997)]. In 1995, Eastman Kodak filed a complaint under U.S. trade law against anti-competitive practices by its Japanese competitor Fuji in the market for photographic film and paper. Kodak's main complaint was that the ED contracts between Fuji and a number of Japanese wholesalers represented a severe obstacle in reaching Japanese consumers. Interestingly, the U.S. government took this case to the World Trade Organization (WTO) in 1996 where it was subsequently struck down with the argument that Kodak's complaint not be addressed to the WTO but rather to the Japanese antitrust authority, the Japanese Fair Trade Commission [WTO (1998)]. The markets for automobiles, flat glass and paper provide other examples, where ED contracts between Japanese manufacturers and their distributors have been blamed for the failure of U.S. producers to gain significant market share. Similar complaints have been made concerning exclusive dealing arrangements in a wide range of other industries and countries, including telecommunication in Europe, Hong Kong and Korea, fertilizer in Norway, ice cream in Germany, heart disease drugs in France, automobiles in the United Kingdom, bottle and biscuit manufacturing in Colombia, high-fructose corn syrup in Mexico, and artificial teeth in the United States [U.S. Department of Justice (2000)].

In many member countries of the European Union, automobiles are usually sold through networks of exclusive dealers. But recently the European Commission has proposed new rules on distribution arrangements for automobiles that restrict the use of ED. The main reason given by the Commission is that ED contributes to restricting intra-EU trade in automobiles and prevents a convergence in pre-tax prices [see, for instance, Monti (2000)]. By contrast, ED is less common in the US automobile industry, where in 1989 about $30 \%$ of dealers held multiple franchises selling competing brands. An arrangement whereby competing brands are sold through the same agents is 
referred to as a common agency $(\mathrm{CA})$.

In modeling manufacturers' choices between ED and CA we follow Besanko and Perry (1993) who suggest the following basic tradeoff: CA may lead to weaker interbrand competition than ED, but may cause suboptimal investment by manufacturers in their dealer network, as these investments provide positive externalities for competing brands. Examples of such investments are training for retailers' employees, support for local advertising and promotion, and financing for retail outlets. ${ }^{1}$ Both the severity of the interbrand externality and the degree of interbrand competition should be affected by the level of trade costs. As these costs change, the trade-off between these two aspects changes as well, which in turn affects the choice of contracts. We examine games between domestic and foreign manufacturers competing in the domestic market. Each manufacturer chooses between $\mathrm{ED}$ and $\mathrm{CA}$ and then selects how much to invest in its retailers and what wholesale price to charge. We first start with the simplest possible case: one domestic and one foreign firm and then extend the analysis to the three firm case with either two domestic or two foreign firms.

We show two main points. First, the domestic manufacturer has an incentive to use ED when the trade barrier is high, because this contract can prevent the entry of a foreign manufacturer (and thus trade) whereas CA would not prevent such entry. This result is very robust, since it exists whatever the characteristics of the products (i.e., the degree of substitution), whatever the degree of interbrand externality, and no matter whether there are two or three firms (and thus one or two domestic firms). Although the use of ED does not necessarily decrease welfare, it does so when the products are good substitutes. Second, the manufacturers have an incentive to use CA when the barrier to trade is low to mitigate interbrand competition. This incentive exists especially when the products are good substitutes and the interbrand externality is not very strong. The use of CA in this case decreases domestic welfare. Since, in both instances, the choice of contracts reduces or prevents imports, our results show that contractual arrangements can act as barriers to trade and, when switches in contracts occur, they are

\footnotetext{
${ }^{1}$ This reason for ED was also discussed by Marvel (1982). Another reasons for choosing ED arises when manufacturers are incompletely informed about the retail cost. Gal-Or (1991) and Martimort (1996) show that ED may be preferred by manufacturers to CA as this may make it easier to extract information rents from retailers. Specifically, the manufacturer may use the observed behavior of competing agents to learn about the cost of their own agent, provided these costs are correlated.
} 
substitutes for standard trade barriers.

As far as competition policy is concerned, the results of this paper suggest two main conclusions. First, one cannot assume that, from a domestic welfare point of view, CA and ED are systematically 'good' or 'bad'. Their effect depends very much on the market environment (level of trade barriers, degree of substitution among products, the degree of spillover, etc.). Second, competition policy needs to be especially active when products are good substitutes. It is in this particular case that the use of ED (when barriers to trade are high) and the use of CA (when they are low) are welfare decreasing.

This paper belongs to the emerging literature on the organization of firms and industries in an international environment. Recent papers on this broad topic include Grossman and Helpman (2001) who use an incomplete contract approach to understand in-house and outsourcing activities in an integrated world, and Spencer and Qiu (2001) who consider whether informal procurement within Japanese keiretsu acts as a barrier to trade. Articles more specifically aimed at the links between manufacturers and distribution in international markets include Fargeix and Perloff (1989) which, to our knowledge, is the first theoretical paper on this issue, Raff and Schmitt (2002) on exclusive territory contracts, and Richardson (2002) who uses a spatial approach to look at the interaction between trade policy and market access.

The paper is organized as follows. In the next section, we build a model where the choice of contract involves a trade-off between an interbrand externality and interbrand competition. In Sections 3 and 4, we investigate the equilibrium choices of two manufacturers, one domestic and one foreign. In Section 5, we consider the welfare implications in the two manufacturer case. Section 6 extends the analysis to the case with three manufacturers, and Section 7 concludes.

\section{The Model}

Consider an industry composed of domestic manufacturers and foreign manufacturers who produce imperfectly substitutable goods for sale in the domestic market. We consider two main cases: the case with two products (one domestic and one foreign), and the case with three products (one domestic and two foreign, and two domestic and one foreign). The production technology exhibits constant marginal cost, which we normalize to zero. The 
representative domestic consumer has a quasi-linear utility function:

$$
U\left(x_{1}, \ldots, x_{n}, y\right)=\sum_{i=1}^{n} x_{i}-\frac{1}{2} \sum_{i=1}^{n} x_{i}^{2}-b \sum_{i=1}^{n} \sum_{j \neq i}^{n} x_{i} x_{j}+y
$$

where $x_{i}$ denotes the consumption of manufacturer $i$ 's product, $y$ the consumption of the numeraire good, and $n$ is either 2 or 3 . Parameter $b$ ( $b \in$ $[0,1])$ reflects the degree of product substitutability between any pair of products. If $b=0$, the products are not substitutable and each producer acts as a monopolist; if $b=1$, the goods are perfect substitutes. Denoting income by $M$ and the retail price of product $i$ by $p_{i}$, the consumer's budget constraint is

$$
\sum_{i} p_{i} x_{i}+y=M
$$

Maximizing (1) subject to (2) and inverting the resulting first-order conditions yields a demand function for each product. The exact specification of these demands depends on the total number of products on the market. We therefore postpone the derivation of these demands.

To distribute their products to consumers, manufacturers require the services of retailers. We assume that there are many ex ante identical retailers, each of whom can provide a retail service at marginal cost $c<1$. Retailers carrying a foreign product also incur a trade cost $t$ per unit, which may reflect both transportation costs and trade barriers and is treated here as a resource cost. Each manufacturer may impose an ED contract on its retailers. The alternative is CA, where retailers carry at least two competing brands.

Manufacturer $i$ sets a wholesale price $w_{i}$. In addition, he must choose how much to invest in his distribution chain. We follow Besanko and Perry (1993) in treating this investment as lowering the marginal cost of the retailers carrying his product. The manufacturer's investment is not specific to a particular retailer, but rather benefits all of his retailers. However, if a retailer is a common agent, the investment may be less effective in reducing the selling cost of one's own brand and it may also benefit the rival brands sold by the common agent. ${ }^{2}$ In particular, by investing an amount $I_{i}$ at a cost of $(k / 2) I_{i}^{2}$,

\footnotetext{
${ }^{2}$ For instance, the investment may be in providing assistance for the retailers' advertising and promotional activities, or in increasing the efficiency of the retailers' personnel or management. Under CA one would expect the return to this investment to be lower than under ED, since part of the retailers' time and resources are devoted to selling com-
} 
manufacturer $i$ lowers the marginal cost of selling its own brand by $\hat{I}_{i}$, where $\hat{I}_{i}=\left\{\begin{array}{l}I_{i}, \quad \text { if the retailer is an exclusive dealer of brand } i \\ \lambda I_{i}+(1-\lambda)\left(\frac{\sum_{j \neq i}^{m} I_{j}}{m}\right), \quad \text { if the retailer carriers } m \text { additional brands, }\end{array}\right.$ where $\lambda \in(0,1]$. The parameter $\lambda$ shows how much manufacturer $i$ 's brand benefits from his own investment and how large the spillover is from the investments of other manufacturers selling their brands through the same retailer. The key however is the spillover effect. ${ }^{3}$ If $\lambda=1$, there are no externalities between the manufacturers. This corresponds to the case of ED. CA is hence characterized by $\lambda<1$. The lower is $\lambda$, the greater is the incentive to freeride on the investments of the other manufacturers.

The strategic interactions between the manufacturers and between them and their retailers can be summarized by the following four-stage game. In the first stage, each manufacturer chooses whether to impose an ED contract on its retailers or to allow CA with other manufacturers. In the second stage, each manufacturer decides whether or not to enter the market. In the third stage, manufacturers choose their wholesale prices and investment levels. In the fourth stage, retailers choose retail prices and consumers then make their purchase decisions.

In the next two sections we solve this game for pure-strategy subgameperfect equilibria for the simplest case: the case of one domestic and one foreign manufacturer. It is an interesting case, not only because it allows us to derive results in a straightforward way but also because it gives us strong results that are shown to hold in the more complex cases. With two manufacturers, a key part of the game becomes very simple. Specifically, if at least one manufacturer chooses to offer ED contracts to his retailers, then both manufacturers necessarily offer ED contracts in equilibrium whether or not the other manufacturer wishes to do so.

peting brands. Alternatively, one could model the investment as boosting demand for the manufacturer's product, for instance by informing potential customers about the existence of the product or the location of retailers. Here the investment would be rendered less effective by $\mathrm{CA}$, if some of the potential customers visiting a retailer end up buying a competing product. Whether the investment lowers marginal cost or raises demand does not matter for the results.

${ }^{3}$ An alternative formulation of the externality, reminiscent of the way R\&D spillovers are often modelled, would be to set $\hat{I}_{i}=I_{i}+(1-\lambda) \sum_{j \neq i}^{m} I_{j} / m$. Our computations show that this formulation would yield qualitatively the same results as the one we chose. 


\section{Equilibrium Prices and Investment}

Since there is just one domestic and one foreign product in this simple environment, we use a single index $i$ to denote whether a product (or a firm) is domestic or foreign $(i=h, f)$. Price competition among retailers ensures that the equilibrium retail price of brand $i$ is equal to

$$
\tilde{p}_{i}=w_{i}+\delta_{i} t+c-\hat{I}_{i}, \quad i=h, f, \quad \text { where } \delta_{h}=0, \delta_{f}=1 .
$$

Manufacturer $i$ 's profit maximization problem can then be stated as follow:

$$
\max _{w_{i}, I_{i}} w_{i} D_{i}\left(\tilde{p}_{i}, \tilde{p}_{j}\right)-\frac{k}{2} I_{i}^{2}
$$

where the demand for product $i$ in the two product environment is given by

$$
D_{i}\left(\widetilde{p}_{i}, \widetilde{p}_{j}\right)=\frac{1-b-\widetilde{p}_{i}+b \widetilde{p}_{j}}{1-b^{2}}, \quad i, j=h, f ; \quad i \neq j .
$$

The first-order conditions for this problem are

$$
\begin{aligned}
w_{i} & : \quad D_{i}+w_{i} \frac{\partial D_{i}}{\partial p_{i}}=0 \\
I_{i} & : \quad-w_{i}\left[\lambda \frac{\partial D_{i}}{\partial p_{i}}+(1-\lambda) \frac{\partial D_{i}}{\partial p_{j}}\right]-k I_{i}=0 .
\end{aligned}
$$

The first condition states that a manufacturer's optimal wholesale price equates his residual marginal revenue with the marginal production cost. The second condition shows that the optimal investment balances the marginal benefit with the marginal cost of investment. The marginal benefit of investment is the sum of two effects: (1) a direct effect that arises because investment reduces the retail price of the firm's own product, which in turn raises residual demand ; (2) a strategic effect that occurs because the investment also reduces the retail price of the rival product, which lowers residual demand. The difference between $\mathrm{ED}$ and $\mathrm{CA}$ is that under $\operatorname{ED}(\lambda=1)$ the strategic effect disappears and the direct effect becomes stronger, thus ceteris paribus raising investment. To ensure that the marginal benefit of investment is positive and that second-order conditions in the two-firm case are satisfied we assume that $\lambda>b /(1+b)$ and $k>1 /(2+b)(1-b)$. 
Using (5) in (7), we can express the profit-maximizing investment level as a linear and increasing function of the wholesale price

$$
I_{i}=w_{i} \frac{[\lambda(1+b)-b]}{k\left(1-b^{2}\right)} .
$$

We can also rewrite (6) as

$$
A_{i}-2 w_{i}+b w_{j}+[\lambda(1+b)-b] I_{i}-[\lambda(1+b)-1] I_{j}=0,
$$

where $A_{h}=(1-b)(1-c)+b t$ and $A_{f}=(1-b)(1-c)-t$. Substituting for $I_{i}$ and $I_{j}$ from (8), we can turn (9) into a system of equations in wholesale prices:

$$
\begin{aligned}
w_{i}= & \frac{k\left(1-b^{2}\right) A_{i}}{2 k\left(1-b^{2}\right)-(\lambda(1+b)-b)^{2}} \\
& +\left(\frac{b k\left(1-b^{2}\right)+(\lambda(1+b)-b)(1-\lambda(1+b))}{2 k\left(1-b^{2}\right)-(\lambda(1+b)-b)^{2}}\right) w_{j} .
\end{aligned}
$$

Solving this system, we get as equilibrium wholesale prices

$$
\begin{aligned}
\tilde{w}_{i}= & \frac{k\left(1-b^{2}\right)}{B}\left\{\left[2 k\left(1-b^{2}\right)-(\lambda(1+b)-b)^{2}\right] A_{i}\right. \\
& \left.+\left[b k\left(1-b^{2}\right)+(\lambda(1+b)-b)(1-\lambda(1+b))\right] A_{j}\right\},
\end{aligned}
$$

where $B=\left[2 k\left(1-b^{2}\right)-(\lambda(1+b)-b)^{2}\right]^{2}-\left[b k\left(1-b^{2}\right)+(\lambda(1+b)-b)(1-\lambda(1+b))\right]^{2}$. We can then compute the equilibrium sales volume

$$
\tilde{x}_{i}=\frac{\tilde{w}_{i}}{1-b^{2}}
$$

and equilibrium profit

$$
\tilde{\pi}_{i}=\frac{\tilde{w}_{i}^{2}}{1-b^{2}}\left[1-\frac{(\lambda(1+b)-b)^{2}}{2 k\left(1-b^{2}\right)}\right] .
$$

If the barrier to trade is high enough, the foreign manufacturer cannot sell in this market and the domestic manufacturer is the only seller. In this case, the demand faced by the domestic product is simply $p_{h}=1-x_{h}$, and it is easy to derive that in equilibrium $w_{h}^{m}=x_{h}^{m}=\frac{k(1-c)}{2 k-1}, I_{h}^{m}=\frac{(1-c)}{2 k-1}$, $\pi_{i}^{m}=\frac{(1-c)^{2} k}{2(2 k-1)}$.

Consider first how the duopoly equilibrium changes with the trade cost taking as given the contract between the producers and the retailers. 
Lemma 1 (i) The equilibrium investment levels, wholesale prices and sales volumes are linear in the trade cost. (ii) As the trade cost increases, the equilibrium investment level, wholesale price and sales volume increase for the domestic firm and decrease for the foreign firm whether the products are sold under exclusive dealing or under common agency contracts.

Proof: See Appendix

The linearity of demand and perfect competition at the retail level explain why investment, wholesale prices and sales volumes are linear in $t$. The domestic wholesale price changes in the opposite direction from the foreign wholesale price when $t$ changes, because a higher trade cost increases (decreases) the residual demand faced by the domestic (foreign) manufacturer.

Since profit is a quadratic function of the wholesale price, we may state:

Lemma 2 As the trade cost changes, the equilibrium profit for each manufacturer changes in the same direction as its wholesale price. Specifically, the domestic manufacturer's profit increases at an increasing rate $\left(\partial \tilde{\pi}_{h} / \partial t>0\right.$, $\left.\partial \tilde{\pi}_{h}^{2} / \partial t^{2}>0\right)$ and the foreign manufacturer's profit decreases at a decreasing rate $\left(\partial \tilde{\pi}_{f} / \partial t<0, \partial \tilde{\pi}_{f}^{2} / \partial t^{2}>0\right)$.

Proof: See Appendix.

Lemma 2 describes a standard result in the literature, since it says that the increased competition brought by trade liberalization decreases the domestic manufacturer's profit and increases the foreign manufacturer's profit. The value added of the Lemma is to confirm this is the case for both types of contract. The interesting issue is to identify the forces that determine the choice of contract given a particular level of $t$ and to derive the equilibrium contracts. This is what we do in the next section.

\section{Equilibrium Contracts}

In order to examine how contracts are chosen in equilibrium, we have to compare profit levels under the two contract arrangements knowing that CA can only emerge in equilibrium if both manufacturers prefer it over ED. Proposition 1 summarizes the results in free trade (see also Besanko and Perry (1993)). 
Proposition 1 In free trade, both manufacturers adopt a common agent unless the investment spillover is sufficiently strong and/or the degree of substitution between products is sufficiently low in which case both manufacturers adopt an exclusive dealing contract. Specifically, there exists a critical value $\lambda_{0}(b)$ such that $\pi_{i}^{C A}(\lambda, b)>\pi_{i}^{E D}(1, b)$ for $\lambda_{0}(b)<\lambda<1$ and $\tilde{\pi}_{i}^{C A}(\lambda, b)<\tilde{\pi}_{i}^{E D}(1, b)$ for $b /(1+b) \leq \lambda<\lambda_{0}(b)$.

Proof: See Appendix.

The reason that CA raises profit for high $\lambda$ is that it acts as a commitment to keep investment low and thus raise retail prices above the level achievable under ED. But for a low enough $\lambda$ (and hence a strong enough externality) investment under CA becomes too small and manufacturers are hence better off with ED.

Since CA tends to reduce investment and thus output as compared to ED, the market tends to be more competitive under ED than under CA. When the barrier to trade is high, ED is particularly detrimental to the foreign manufacturer which then faces a particularly low residual demand. This implies that the trade cost at which the profit of the foreign manufacturer is zero is lower under ED than under CA. Denoting the prohibitive levels of the trade cost under ED and $\mathrm{CA}$ by $t_{p}^{E D}$ and $t_{p}^{C A}$, respectively, the implication of the competitive effect of ED is confirmed by Proposition 2 .

Proposition 2 In equilibrium, the prohibitive level of the trade cost is lower under exclusive dealing than under common agency $\left(t_{p}^{E D}<t_{p}^{C A}\right)$.

Proof: See Appendix

This is a strong result which holds irrespective of the degree of substitution between products and irrespective of the degree of interbrand spillover associated with the manufacturer's investment. Its implication is clear: ED constitutes a barrier to entry when associated with significant trade costs. We will come back to this point.

Before proceeding further, it is useful to have a better understanding of why these two propositions hold. We can gain some useful insights by considering how marginal changes of the parameter $\lambda$ affect equilibrium profits. Taking into consideration that the equilibrium retail prices can be written as $p_{i}\left(\tilde{w}_{i}, \lambda, \tilde{I}_{i}, \tilde{I}_{j}\right)$ and applying the envelope theorem, we obtain three distinct 
effects:

$$
\begin{aligned}
\operatorname{sign}\left\{\frac{d \tilde{\pi}_{i}}{d \lambda}\right\}= & \operatorname{sign}\left\{\frac{\partial D_{i}}{\partial p_{j}}\left(\frac{\partial p_{j}}{\partial w_{j}} \frac{\partial \tilde{w}_{j}}{\partial \lambda}+\frac{\partial p_{j}}{\partial I_{j}} \frac{\partial \tilde{I}_{j}}{\partial \lambda}\right)\right. \\
& \left.+\left(\frac{\partial D_{i}}{\partial p_{i}} \frac{\partial p_{i}}{\partial I_{j}} \frac{\partial \tilde{I}_{j}}{\partial \lambda}\right)+\left(\frac{\partial D_{i}}{\partial p_{i}} \frac{\partial p_{i}}{\partial \lambda}+\frac{\partial D_{i}}{\partial p_{j}} \frac{\partial p_{j}}{\partial \lambda}\right)\right\}
\end{aligned}
$$

The first expression on the right-hand side is the strategic effect. A change in $\lambda$ affects manufacturer $i$ 's residual demand $D_{i}$ indirectly, because it changes both the level of investment and the wholesale price of manufacturer $j$ and hence $j$ 's retail price. From (8) we know that $\partial \tilde{I}_{j} / \partial \lambda$ has the same sign as $\partial \tilde{w}_{j} / \partial \lambda$. Assume then that $\partial \tilde{w}_{j} / \partial \lambda>0$. When this is the case, a decrease in $\lambda$ reduces $\tilde{w}_{j}$, thus decreasing $p_{j}$ and hence also $D_{i}$. This effect would tend to decrease manufacturer $i$ 's profit when $\lambda$ is reduced. However, since $\partial \tilde{I}_{j} / \partial \lambda>0$, the decrease in $\lambda$ also decreases $j$ 's incentive to invest which raises $p_{j}$ and hence $D_{i}$. If the effect on $\tilde{I}_{j}$ is stronger than the effect on $\tilde{w}_{j}$ then the strategic effect associated with a decrease in $\lambda$ increases $i$ 's profit by mitigating the rivalry between the two manufacturers.

The second term can be described as a free-rider effect. A decrease in $\lambda$ lowers manufacturer $j$ 's incentive to invest, since it benefits from a stronger spillover from $i$. This effect must increase $i$ 's retail price and thus decrease the demand for product $i$. Hence, with the free-rider effect, a decrease in $\lambda$ is detrimental to manufacturer $i$ 's profit.

The third effect is a rent-shifting effect. This effect occurs only if the two firms have different levels of investment. Suppose then that $i$ is the domestic manufacturer and $t$ is positive (but not prohibitive) so that $\tilde{I}_{i}>$ $\tilde{I}_{j}$. A reduction in $\lambda$ reduces the effectiveness of investment and increases the spillover from the rival's investment, changing retail prices and hence demand. But these effects act differently on the two manufacturers. In particular, $i$ 's big investment becomes less effective while he benefits only relatively little from the greater spillover from $j$ 's small investment. The opposite is true for $j$ : while his small investment becomes less effective, he benefits from an increased spillover from $i$ 's big investment. Hence a lower $\lambda$ raises $p_{i}$ relative to $p_{j}$, shifting market share and rent from the domestic to the foreign manufacturer.

As must be apparent, a decrease in $\lambda$ has contradictory effects and several of them tend to decrease manufacturer $i$ 's profit, at least when it is a domestic 
manufacturer. Using (5), we can rewrite (14) as

$\operatorname{sign}\left\{\frac{d \tilde{\pi}_{i}}{d \lambda}\right\}=\operatorname{sign}\left\{b\left[\frac{\partial \tilde{w}_{j}}{\partial \lambda}-\lambda \frac{\partial \tilde{I}_{j}}{\partial \lambda}\right]+\left[(1-\lambda) \frac{\partial \tilde{I}_{j}}{\partial \lambda}\right]+\left[(1+b)\left(\tilde{I}_{i}-\tilde{I}_{j}\right)\right]\right\}$,

where the terms in square brackets represent the three effects identified above.

Suppose we have free trade so that investments are symmetric and the last term, representing the rent-shifting effect, is zero. If $\lambda=1$, the second term (corresponding to the free-rider effect) is also equal to zero. The effect of a marginal decrease in $\lambda$ then depends on the sign of the first term (the strategic effect). Using (11), it is easy to show that $\partial \tilde{w}_{j} / \partial \lambda>0$, which implies that $\partial \tilde{I}_{j} / \partial \lambda$ is also positive. ${ }^{4}$ It can also be shown that in free trade the strategic effect is unambiguously negative for $\lambda=1$, so that at that point a marginal decrease in $\lambda$ must increase profit. If we lower $\lambda$, the freerider effect becomes positive and the strategic effect less clearly negative and eventually positive; hence a reduction in $\lambda$ ultimately lowers profit. Also note that lowering $b$ has a similar effect as reducing $\lambda$, since it decreases the weight of the strategic effect. This discussion provides intuition for Proposition 1.

Suppose now that $t$ is positive. This means that in (15) the rent-shifting effect becomes relevant. Its sign is positive for the domestic manufacturer and negative for the foreign manufacturer. By itself this effect means that as $\lambda$ falls, rent is shifted from the domestic to the foreign manufacturer. Since the magnitude of this effect depends on $\left(\tilde{I}_{i}-\tilde{I}_{j}\right)$, this shift in rent becomes stronger as $t$ increases. In turn this suggests that for high $t$ the foreign manufacturer may have higher profits under CA than under ED and vice versa for the domestic manufacturer. If this is the case, the level of the trade cost at which the foreign manufacturer makes no profit under ED $\left(t_{p}^{E D}\right)$ must generate positive profit under CA. This not only provides an intuition for Proposition 2 but it also suggests that the domestic manufacturer systematically prefers ED to CA around the prohibitive barrier to trade.

The above analysis can be conveniently summarized by Figures 1 and 2 . In Figure 1, we have assumed that the investment spillover is sufficiently low ( $\lambda$ near 1$)$ and that the degree of substitution between products is relatively high ( $b$ near 1$)$ so that, in free trade $\tilde{\pi}_{i}^{C A}>\tilde{\pi}_{i}^{E D}$. Figure 2 illustrates the opposite case: one where the spillover is high ( $\lambda$ is low) and the degree of

\footnotetext{
${ }^{4}$ Using (11) and assuming free trade, $\tilde{w}_{i}=\frac{k\left(1-b^{2}\right)(1-b)(1-c)}{k\left(1-b^{2}\right)(2-b)-(1-b)(\lambda(1+b)-b)}$. Hence $\partial w_{i} / \partial \lambda>0$.
} 
substitution between the two products is low ( $b$ is low). These figures are useful to state two important results, summarized in Propositions 3 and 4.

Proposition 3 (i) If the degree of substitution is high and/or the degree of investment spillover is low, there is always a non-prohibitive trade cost $\hat{t}$ such that, as $t$ decreases below $\hat{t}$, equilibrium contracts switch from exclusive dealing to common agency. (ii) If the degree of substitution is low and/or the degree of investment spillover is high, both manufacturers adopt exclusive dealing irrespective of the level of the non-prohibitive trade cost.

The first result can be easily seen from Figure 1. When $t$ is nearly prohibitive, the domestic manufacturer prefers ED to CA. In a two-manufacturer, two-product case, this ensures that ED is the equilibrium contractual arrangement even if the other manufacturer always prefers CA (in Figure 1, the foreign manufacturer prefers CA for all non-prohibitive values of $t$ ). A common agency contract can therefore emerge only if the domestic manufacturer also prefers it to ED. This occurs for $t<\hat{t}$. In Figure 2, the domestic manufacturer always prefers ED irrespective of $t$. This is sufficient to ensure that ED is the only equilibrium contract in a two-manufacturer environment irrespective of the foreign manufacturer's preferences.

If these results depend on the degree of investment spillover, they also depend on the degree of substitution between products. In particular, when products are strongly differentiated (as in Figure 2), ED is always preferred. If products are not strongly differentiated (as in Figure 1), trade liberalization by fostering interbrand competition induces the domestic manufacturer to switch contract to $\mathrm{CA}$ as the latter contract is more helpful than ED at mitigating the competitive impacts of trade liberalization. Hence the only possible switch in contract induced by trade liberalization is one from exclusive dealing to common agency. We have here a case where one manufacturer substitutes private contracting for traditional trade barriers in order to minimize the economic impacts of trade liberalization. ${ }^{5}$

The model has also interesting results when the trade cost is high. In particular,

Proposition 4 In the range of trade costs $t_{p}^{E D} \leq t \leq t_{p}^{C A}$ exclusive dealing acts as a prohibitive barrier to trade. Specifically, (i) the domestic manufacturer adopts exclusive dealing and the foreign manufacturer cannot trade; (ii) the foreign manufacturer would trade under a common agency contract.

\footnotetext{
${ }^{5}$ See Raff and Schmitt (2002) for similar results with exclusive territory contracts.
} 
This result is interesting because ED acts here as a barrier to trade above and beyond the effect of $t$ itself. Readers familiar with the industrial organization literature on ED might think that this is nothing else than the foreclosure result that arises with ED when wholesale prices are restricted to linear (see Bernheim and Whinston, 1998) and there is a large cost asymmetry among manufacturers (see Comanor and Frech, 1985; Mathewson and Winter, 1987). In part this is indeed the case, since the foreign manufacturer faces a barrier to trade that the domestic firm does not. However, the standard foreclosure result comes from the fact that a manufacturer with a cost advantage signs up exclusive dealing contracts with all the existing retailers thereby making entry impossible. This feature does not exist in the present model, since we have a large number of perfectly competitive retailers. Perfect competition at the retail level has two implications. First, a manufacturer can only set linear wholesale prices. Second, it is not that the foreign manufacturer could not find independent retailers to sign a retailing contract with. Simply, the foreign manufacturer chooses not to sell in the domestic market with ED, because he cannot make a profit and the domestic manufacturer prefers ED to CA solely because the former contract does not involve spillovers and thus does not shift rent to the foreign manufacturer.

\section{Welfare}

In this section we want to identify what the adoption of different contracts implies for domestic social welfare. There are two cases we are particularly interested in: (i) a switch from ED to CA when the trade barrier is low; and (ii) the domestic manufacturer's monopolization of the market through ED when the trade barrier is high.

First, consider the case where the trade barrier is non-prohibitive. Here the welfare effect of a switch to $\mathrm{CA}$ can be decomposed into a change in profits and a change in consumer surplus. Note that CA will be adopted only if it yields both manufacturers a higher profit than ED. Hence the move to CA must lower domestic social welfare if it reduces consumer surplus. Given the quasi-linear utility function, the consumer surplus associated with consuming quantities $x_{h}$ and $x_{f}$ is

$$
C S=x_{h}+x_{f}-\frac{1}{2}\left(x_{h}^{2}+x_{f}^{2}\right)-b x_{h} x_{f}-p_{h} x_{h}-p_{f} x_{f}
$$


Defining the average quantity sold on the market as $\bar{x} \equiv\left(x_{h}+x_{f}\right) / 2$, the difference between the domestic and the foreign sales as $\Delta \equiv x_{h}-x_{f}$, and substituting for $p_{f}$ from the demand function, consumer surplus can be rewritten as

$$
C S(\bar{x}, \Delta)=2 \bar{x}-(1+b) \bar{x}^{2}-2 p_{h} \bar{x}-\frac{1}{4}(1-b) \Delta^{2}-(1-b) x_{f} \Delta .
$$

Hence consumer surplus is essentially a function of the average quantity sold on the market and of the difference in market share between the two firms. Not surprisingly, consumer surplus is decreasing in the difference in market shares and increasing in the average quantity sold. Differentiating consumer surplus and rearranging, the effect on consumer surplus of a marginal change in $\lambda$ is equal to

$$
\frac{d C S}{d \lambda}=\left[(1-b)\left(x_{h}-x_{f}\right)-2 \bar{x} \frac{\partial p_{h}}{\partial \bar{x}}\right] \frac{d \bar{x}}{d \lambda}-\frac{(1-b)}{2}\left[3 x_{f}-x_{h}\right] \frac{d \Delta}{d \lambda} .
$$

The first expression in square brackets is unambiguously positive, since $x_{h} \geq$ $x_{f}$ and $\partial p_{h} / \partial \bar{x}<0$. The second expression in square brackets is positive for low values of $t$ but negative for high values of $t$. The total effect on consumer surplus of a marginal change in $\lambda$ can then be viewed as a weighted sum of the impact of this change on the average quantity sold and on the redistribution of market shares. We show below that consumer surplus and hence welfare unambiguously falls with a lower $\lambda$ if $b$ and $\lambda$ are sufficiently close to 1 , or if $t$ is not too large. This implies that a switch in contract from ED to CA unambiguously reduces domestic social welfare under these conditions.

Second, suppose we are in the range where the domestic manufacturer chooses ED over CA with the result that there is no longer trade. The welfare effect of choosing ED over CA in this case is generally ambiguous. Domestic consumers are hurt, since they face a domestic monopoly instead of a duopoly, thus paying a higher price and facing less product variety. On the other hand, under CA rent is shifted to the foreign manufacturer. When the products are good substitutes, however, it is straightforward to predict how choosing ED over CA will affect welfare: competition among products under CA must yield higher domestic welfare as there is necessarily a strong pro-competitive effect, consumers benefit from greater product variety, and the rent being shifted to the foreign manufacturer is small. On the other hand, if the products are poor substitutes it is easy to provide examples in which social welfare is higher under ED and domestic monopoly. Proposition 5 summarizes the results: 
Proposition 5 (i) Common agency yields lower domestic social welfare than exclusive dealing around free trade. More generally if $t<t_{p}^{E D}$, common agency leads to lower domestic social welfare than exclusive dealing when the externality is not too large and the products are sufficiently close substitutes. (ii) If $t_{p}^{E D} \leq t \leq t_{p}^{C A}$, exclusive dealing leads to lower domestic social welfare when products are sufficiently close substitutes.

Proof: See Appendix.

Recall from the previous section that a switch in contract from ED to $\mathrm{CA}$ requires both a high degree of substitution and a low degree of investment spillover. But these are exactly the conditions under which welfare has a tendency to fall when this switch occurs. These conditions are not very surprising. In particular, a high degree of substitution ensures that, associated with the switch in contract, any redistribution of market shares has little impact on consumers. Hence, the main effect takes place through the average quantity sold on the market and a switch to CA tends to decrease the average quantity irrespective of the non-prohibitive trade barrier.

What policy implications emerge from this analysis? Clearly whether the trade barrier is high or low, a high degree of substitution between products is a key indicator that the manufacturers' choice of contract is bad for domestic welfare; competition policy should therefore be active whether ED or $C A$ is chosen. The specific recommendations for how competition policy should deal with ED and CA when products are close substitutes differ dramatically depending on the level of trade barriers. If trade barriers are high, competition policy should prohibit ED. If trade barriers are low, competition policy should not be concerned with ED, but rather with CA.

\section{The Three-Manufacturer Case}

There are two possible cases: one domestic manufacturer and two foreign ones, or two domestic manufacturers and a single foreign one. In each of these two environments, CA may involve the three products together or just two of them and it may involve products from the same or from different origins. It is useful to investigate these cases for two reasons. First, the three-manufacturer case opens new interesting questions. For instance, are there circumstances where the foreign manufacturers distribute their products through CA? Does this help them penetrate the domestic market? Second, we would like to know whether the results found in the two-manufacturer 
case extend to the three-manufacturer case. As the nature of the threemanufacturer problem is very close to the two-manufacturer case just derived, we do not provide a complete derivation of the equilibria but only highlight two main points. ${ }^{6}$

First,

Proposition 6 Common agencies selling only foreign products do not improve foreign manufacturers' market access.

Proof: See Appendix

This result comes from the fact that, like in the two manufacturer case, the prohibitive level of the trade cost is solely determined by the domestic manufacturer's choice of contract. Hence, as long as the domestic manufacturer sells its product through exclusive retailers, the prohibitive level is the same whether the two foreign manufacturers sell through common agents or not. If the domestic manufacturer agreed to form a three product CA, then trade would occur for a wider range of trade costs (up to $t_{p}^{C A}$ ). However, this is not a profitable strategy for the domestic manufacturer and as a result, for $t \geq t_{p}^{E D}$, he remains a monopolist. This implies that, even in a three-manufacturer environment, a single domestic manufacturer has a strong influence on foreign manufacturers' market access provided that the trade cost is high.

Second, we want to verify that the three-manufacturer case produces similar results as the two-manufacturer case. We need simulations to identify the equilibrium choice of contracts. We therefore impose specific values on the degree of substitution between products $(b)$, the unit retail cost $(c)$ and the investment cost parameter $(k)$. We then ask what the subgame-perfect Nash equilibria of the game are for different values of the externality $(\lambda)$ and the trade cost $(t)$.

Figure 3 illustrates the case of two domestic manufacturers and one foreign manufacturer in $(t, \lambda)$ space. Consistent with our previous analysis, it shows that the prohibitive level of the trade cost is lower under ED: $t_{p}^{E D} \leq t_{p}^{C A}$. All the curves for $t$ below $t_{p}^{E D}$ are indifference curves such that one manufacturer is indifferent between $\mathrm{CA}$ and ED given the other manufacturers' contracts. The two upward sloping curves characterize a domestic manufacturer's choice between having CA with the foreign manufacturer or with the two other manufacturers. The reason they are upward sloping is

\footnotetext{
${ }^{6} \mathrm{~A}$ detailed solution is available from the authors upon request.
} 
that, in response to a rise in $t$, a domestic manufacturer invests more in retailing cost-reducing activities while the foreign manufacturer does the opposite. Hence, as $t$ rises, rent is being shifted from the domestic to the foreign manufacturer with whom it is engaged in a CA. To remain indifferent between CA and $\mathrm{ED}$ when $t$ rises, the domestic manufacturer needs a higher $\lambda$. Exactly the opposite occurs with the foreign manufacturer when it is engaged in a CA with a domestic manufacturer. Therefore the foreign manufacturer's indifference curves are downward sloping. We show only the curve that matters for the equilibrium, which in this case is the one where the foreign manufacturer is indifferent between $\mathrm{ED}$ and having $\mathrm{CA}$ with both domestic manufacturers. Finally, the horizontal line shows the case where one domestic manufacturer is indifferent between $\mathrm{ED}$ and $\mathrm{CA}$ with another domestic manufacturer. ${ }^{7} \mathrm{In}$ every case, the manufacturer prefers $\mathrm{CA}$ for $(t, \lambda)$ above the curve and $\mathrm{ED}$ for $(t, \lambda)$ below the curve.

Figure 3 shows the equilibrium contracts for each of the regions defined by the above curves. To understand how these equilibria are obtained, consider two of them: (CA,CA,CA) and (ED,ED,ED). CA between all three manufacturers is an equilibrium, because above the uppermost upward sloping curve a domestic manufacturer does not want to deviate from a three-product CA and, above the downward sloping curve, the same is true for a foreign manufacturer. ${ }^{8}$ Consider now the north-east region denoted (ED,ED,ED). Below the lower upward sloping curve, a domestic manufacturer wants to deviate from a CA with a foreign manufacturer or from a $\mathrm{CA}$ with the two other manufacturers. A domestic manufacturer would not want to deviate from a $\mathrm{CA}$ with another domestic manufacturer (since we are above the horizontal line). The foreign manufacturer would like to form a CA with one or with both domestic manufacturers. There is no equilibrium (in pure strategies) with CA, since none of the domestic manufacturers wishes to have CA with the foreign manufacturer. The only possible equilibrium is thus ED for the three manufacturers. Similar reasoning can be applied to the other region. Note that Figure 3 has one region with two equilibria involving CA: one

\footnotetext{
${ }^{7}$ When a common agency involves products from the same origin only, the equilibrium wholesale price takes the form $w(\lambda, t)=\frac{n(t)}{d(\lambda)}$. Since $\pi=w^{2}(\lambda, t) R(\lambda)$, a manufacturer is indifferent between keeping CA and switching to ED when $n^{2}(t)\left\{\frac{R(\lambda=1)}{d^{2}(\lambda=1)}-\frac{R(\lambda)}{d^{2}(\lambda)}\right\}=0$. This implies that the roots in $\lambda$ are independent of $t$.

${ }^{8}$ Note that in this region, like in all other ones, (ED,ED,ED) is always an equilibrium contract combination, since one manufacturer alone cannot form a CA.
} 
between a domestic and a foreign manufacturer and the other between the two domestic manufacturers. Finally consider the region to the right of $t_{p}^{E D}$. Both domestic manufacturers choose ED because if they do not, the foreign manufacturer enters at least as long as $t$ is less than $t_{p}^{C A}$.

Figure 3 shows that trade liberalization, when it brings switches in contracts, leads to switches toward CA, not toward ED. Moreover, like in the two-manufacturer case, ED is the domestic manufacturers' contract of choice when the trade barrier is high. In short, the main result found in the twomanufacturer case extends to the case of two domestic manufacturers and one foreign manufacturer.

Consider now the case of two foreign and one domestic manufacturer. Its interesting feature is that the foreign manufacturers may form a $\mathrm{CA}$, whether or not the domestic manufacturer participates. Figure 4 illustrates this case. The interpretation of the curves is similar to that in Figure 3. The striking feature of Figure 4 is that, although trade liberalization brings more CA, equilibria with CA are far more prevalent than in the previous case. Indeed all the regions in Figure 4 except the one where the externality is so strong that no one wants to be involved in a CA (below the horizontal line) are consistent with CA between the two foreign manufacturers. The fact that foreign manufacturers have a stronger incentive to sell their product through CA is not surprising. When the trade barrier is high, the competitive environment is intense for the foreign products and CA helps mitigate it. However, the domestic manufacturer cannot avoid the presence of the foreign products, but does not want to sell its product through $\mathrm{CA}$, because significant rents would then be shifted to the foreign manufacturers.

\section{Conclusions}

In this paper, we examine domestic and foreign manufacturers' choices between exclusive dealing and common agency. We show three main points. First, domestic manufacturers use exclusive dealing when trade barriers are high so as to prevent rents from being shifted to foreign manufacturers. Rents would be shifted under common agency, because foreign manufacturers can benefit much more from domestic manufacturers' investments in their distribution chain than vice versa. Exclusive dealing is adopted whatever the characteristic of the products (i.e., the degree of substitution), whatever the degree of interbrand externality, and no matter whether there are two or 
three manufacturers. Second, manufacturers tend to use common agency when trade barriers are low. This incentive exists especially when the products are good substitutes and the interbrand externality is not very strong. Since the manufacturers want to mitigate interbrand competition, our results show that contracts can act as barriers to trade and, when switches in contracts occur, they are substitutes for standard trade barriers. This confirms the view held by antitrust authorities that private anti-competitive contractual arrangements may gain greater importance as traditional trade barriers are removed and that competition authorities may therefore have to be tough in a free-trade environment.

Third, our analysis implies that competition authorities should be active especially when products are close substitutes, but that the policy they should pursue depends on the level of trade barriers. When trade barriers are high, authorities should be especially concerned with exclusive dealing arrangements by domestic manufacturers. However, when trade barriers are low their attention should turn to common agency arrangements.

These findings are helpful to interpret some of the examples mentioned in the introduction. In the European automobile market, the fact that exclusive dealing agreements have continued to be prevalent despite significant economic integration suggests that the degree of spillover is high and/or the degree of substitution between products is relatively low. A policy aimed at discouraging exclusive dealing would then unambiguously lower the profits of the automobile producers. However this outcome would be achieved by decreasing competition, not by increasing it. In other words, profits would be reduced by decreasing investments and sales, and increasing retail prices. Such a policy would unambiguously reduce social welfare at least if the market was at or near free trade. There is however another interpretation that would more strongly justify the recent EU policy. The use of exclusive dealing in the automobile industry varies a lot across European countries with at least $85 \%$ of the dealers under exclusive contracts in countries like Germany, Italy and in the UK, and with rates below $71 \%$ in countries like Austria, Denmark, Finland, Ireland and Sweden. Since it is doubtful that the degree of spillover or the degree of substitution differs significantly across Europe, it is tempting to conclude that these differences are due to differences in explicit or implicit barriers to trade and that it is those barriers that facilitate the extensive use of exclusive contractual arrangements in the large (automobile producing) countries. In other words, thanks to the bloc exemption granted by the EU Commission, the European market integration would have largely 
by-passed the automobile market.

Finally, a central message of this paper is to show that the use of exclusive dealing is closely linked to the trade environment. By ruling that Kodak's complaint with respect to Fuji's alleged behavior in the Japanese film market was a domestic issue, the WTO would have been essentially correct if it were true that Japanese trade barriers in this market were low. If impediments to trade were significant, however, our analysis suggests that the WTO should have been pro-active not only with respect to the trade barriers themselves but also with respect to the contractual arrangement they induce.

Our model is admittedly simple. In particular, our assumption of perfect competition at the retail level may seem at odds with the above two cases. When the trade barrier is high, the domestic manufacturers' incentive to prevent entry by signing up exclusive contracts with all or at least with the most efficient intermediaries cannot be ruled out. Clearly, this argument goes in the same direction as the one inducing the domestic manufacturer to adopt exclusive dealing developed in this model. Similarly, market power at the retail level implies that the collusive aspect of common agency is enhanced by retailers' ability to internalize price competition. We therefore conclude that the qualitative results of this paper are reinforced by the presence of a limited number of imperfectly competitive retailers.

\section{Appendix}

\section{Proof of Lemma 1:}

Since $\lambda>b / 1+b$ and $b<1$, then from (8), $\frac{\partial \tilde{I}_{i}}{\partial t}$ has the same sign as $\frac{\partial \tilde{w}_{i}}{\partial t}$. Using (12), $\frac{\partial \tilde{x}_{i}}{\partial t}$ has also the same sign as $\frac{\partial \tilde{w}_{i}}{\partial t}$. Note that $t$ can be found only in $A_{h}$ and in $A_{f}$ and that both $A_{h}$ and $A_{f}$ are linear in $t$. This implies that $\frac{\partial \tilde{w}_{i}}{\partial t}$ and thus $\frac{\partial \tilde{x}_{i}}{\partial t}$ and $\frac{\partial \tilde{I}_{i}}{\partial t}$ are independent of $t$. This establishes part (i). To show part (ii), we only need to show that $\frac{\partial \tilde{w}_{h}}{\partial t}>0$ and $\frac{\partial \tilde{w}_{f}}{\partial t}<0$. Using $\widetilde{w}_{h}$ as given by (11),

$$
\frac{\partial \widetilde{w}_{h}}{\partial t}=\frac{k\left(1-b^{2}\right)}{B}\left\{b \beta_{1}-\beta_{2}\right\},
$$

where $B=\beta_{1}^{2}-\beta_{2}^{2}, \beta_{1}=2 k\left(1-b^{2}\right)-(\lambda(1+b)-b)^{2}$ and $\beta_{2}=b k\left(1-b^{2}\right)+$ $(\lambda(1+b)-b)(1-\lambda(1+b))$. Hence, $\frac{\partial \widetilde{w}_{h}}{\partial t}>0$ if and only if $B>0$ and $b \beta_{1}>\beta_{2}$. This second inequality holds if and only if $b k>(\lambda(1+b)-b)(1-\lambda)$. Observe that, since $b<1$, then the condition to have $b \beta_{1}>\beta_{2}$ also implies $B>0$. 
Finally,

$$
\frac{\partial \widetilde{w}_{f}}{\partial t}=\frac{k\left(1-b^{2}\right)}{B}\left\{b \beta_{2}-\beta_{1}\right\}<0,
$$

since $b \beta_{1}>\beta_{2}$, then $\beta_{1}>b \beta_{2}$ when $b<1$. Hence, $\frac{\partial \widetilde{w}_{h}}{\partial t}>0$ and $\frac{\partial \widetilde{w}_{f}}{\partial t}<0$ whenever $\mathrm{b} k>(\lambda(1+b)-b)(1-\lambda)$.

\section{Proof of Lemma 2:}

Since (13) is quadratic in $w_{i}$, sign $\left\{\frac{\partial \tilde{\pi}_{i}}{\partial t}\right\}=\operatorname{sign}\left\{w_{i} \frac{\partial \tilde{w}_{i}}{\partial t}\right\}$ and $\operatorname{sign}\left\{\frac{\partial^{2} \tilde{\pi}_{i}}{\partial t^{2}}\right\}=$ $\operatorname{sign}\left\{\frac{\partial \tilde{w}_{i}}{\partial t}\right\} \operatorname{sign}\left\{\frac{\partial \tilde{w}_{i}}{\partial t}\right\}$. Since $\frac{\partial \tilde{w}_{h}}{\partial t}>0$, then $\tilde{\pi}_{h}$ is increasing at an increasing rate with respect to $t\left(\operatorname{sign}\left\{\frac{\partial \tilde{\pi}_{h}}{\partial t}\right\}>0\right.$, sign $\left.\left\{\frac{\partial^{2} \tilde{\pi}_{h}}{\partial t^{2}}\right\}>0\right)$. Since $\frac{\partial \tilde{w}_{f}}{\partial t}<0$, then $\tilde{\pi}_{f}$ is decreasing at a decreasing rate with respect to $t\left(\operatorname{sign}\left\{\frac{\partial \tilde{\pi}_{f}}{\partial t}\right\}<0\right.$, $\left.\operatorname{sign}\left\{\frac{\partial^{2} \tilde{\pi}_{i}}{\partial t^{2}}\right\}>0\right)$.

\section{Proof of Proposition 1:}

Using the equilibrium wholesale price, the manufacturer's equilibrium profit in free trade $(t=0)$ can be re-written as

$$
\left.\tilde{\pi}_{i}\right|_{t=0}=\frac{k \beta_{1} A^{2}}{2\left(\beta_{1}-\beta_{2}\right)^{2}}
$$

where $\beta_{i}(i=1,2)$ has the same definition as in the Proof of Lemma 1 and $A=A_{h}=A_{f}$. Differentiating this expression with respect to $\lambda$, we get

$$
\frac{\left.d \widetilde{\pi}_{i}\right|_{t=0}}{d \lambda}=\frac{k A^{2}}{2\left(\beta_{1}-\beta_{2}\right)^{3}}\left[-2 \beta_{1}\left(\frac{d \beta_{1}}{d \lambda}-\frac{d \beta_{2}}{d \lambda}\right)+\left(\beta_{1}-\beta_{2}\right) \frac{d \beta_{1}}{d \lambda}\right] .
$$

Since $\beta_{1}>\beta_{2}, \frac{d \beta_{1}}{d \lambda}=-2(1+b)(\lambda(1+b)-b)$ and $\frac{d \beta_{2}}{d \lambda}=(1+b)^{2}(1-2 \lambda)$ then $\frac{d \beta_{1}}{d \lambda}-\frac{d \beta_{2}}{d \lambda}=-\left(1-b^{2}\right)$. It follows that

$$
\operatorname{sign} \frac{\left.d \widetilde{\pi}_{i}\right|_{t=0}}{d \lambda}=\operatorname{sign}\left\{\beta_{1}(1-b)-\left(\beta_{1}-\beta_{2}\right)(\lambda(1+b)-b)\right\}
$$

Hence, for $\lambda=1, \operatorname{sign}\left\{\frac{\left.d \tilde{\pi}_{i}\right|_{t=0}}{d \lambda}\right\}=\operatorname{sign}\left\{-b \beta_{1}+\beta_{2}\right\}<0$ (see Proof of Lemma 1) and for $\lambda=b /(1+b)$, sign $\left\{\frac{\left.d \tilde{\pi}_{i}\right|_{t=0}}{d \lambda}\right\}=\operatorname{sign}\left\{\beta_{1}(1-b)\right\}>0$. We can further show that $\widetilde{\pi}_{i}$ reaches a maximum at $\bar{\lambda}=\frac{2-b^{2}}{(1+b)(2-b)}$ since $\frac{\left.d^{2} \widetilde{\pi}_{i}\right|_{t=0}}{d \lambda^{2}}<$ 0 when evaluated at $\lambda=\bar{\lambda}$. It follows that if $\left.\tilde{\pi}_{i}\right|_{t=0, \lambda=1 / 1+b}>\left.\tilde{\pi}_{i}\right|_{t=0, \lambda=1}$, CA is preferred for all $\frac{b}{1-b} \leq \lambda \leq 1$. If, however, $\left.\tilde{\pi}_{i}\right|_{t=0, \lambda=1 / 1+b}<\left.\widetilde{\pi}_{i}\right|_{t=0, \lambda=1}$, the 
manufacturer's profit is higher with ED when $\frac{b}{1-b} \leq \lambda<\lambda_{0}$ and with CA when $\lambda_{0}<\lambda \leq 1$ (where $\lambda_{0}$ is such that $\left.\tilde{\pi}_{i}\right|_{t=0, \lambda_{0}}=\left.\tilde{\pi}_{i}\right|_{t=0, \lambda=1}$ ). Accordingly, we must simply show that values of $b$ exists such that $\left.\widetilde{\pi}_{i}\right|_{t=0, \lambda=1 / 1+b}<$ $\left.\tilde{\pi}_{i}\right|_{t=0, \lambda=1}$. Using (19), it is easy to find that $\left.\tilde{\pi}_{i}\right|_{t=0, \lambda=1 / 1+b}<\left.\tilde{\pi}_{i}\right|_{t=0, \lambda=1}$ around $b=0$ (but not for $b=1$ ).

\section{Proof of Proposition 2:}

The prohibitive level of the trade barrier is determined by $x_{f}=0$. Using (12) and (11), the prohibitive barrier is

$$
t_{p}(b, \lambda)=\frac{(1-c)[k(1-b)(2+b)-(\lambda(1+b)-b)(2 \lambda-1)]}{k\left(2-b^{2}\right)+\lambda(b-\lambda(1+b))} .
$$

Taking the derivative with respect to $\lambda$, we find that:

$$
\begin{aligned}
\operatorname{sign}\left\{\frac{\partial t_{p}}{\partial \lambda}\right\}= & \left\{-[4 \lambda(1+b)-1-3 b]\left[k\left(2-b^{2}\right)+\lambda(b-\lambda(1+b))\right]\right. \\
& \left.+[2 \lambda(1+b)-b]\left[k(1-b)(2-b)-(2 \lambda-1)\left(\lambda(1+b)-\left(b^{2}\right)\right]\right\}\right)
\end{aligned}
$$

Assuming that $\lambda=1$, sign $\left\{\frac{\partial t_{p}}{\partial \lambda}\right\}=\operatorname{sign}\{-2(1+b) k+1\}<0$ since we require $k>\frac{1}{2\left(1-b^{2}\right)}$. Hence, introducing a small externality (lowering $\lambda$ ) increases the prohibitive rate at least in the neighborhood of $\lambda=1$. When evaluating $\operatorname{sign} \frac{\partial t_{p}}{\partial \lambda}$ at $\lambda=\frac{b}{1+b}$ however, sign $\left\{\frac{\partial t_{p}}{\partial \lambda}\right\}=2 k\left(1-b^{2}\right)>0$ so that we need to compare the level of the prohibitive rates to make sure that $t_{p}^{E D}<t_{p}^{C A}$. With $\mathrm{ED}(\lambda=1)$, the level of prohibitive trade cost is

$$
t_{p}^{E D}=\frac{(1-c)[k(1-b)(2+b)-1]}{k\left(2-b^{2}\right)-1},
$$

and under CA subject to the strongest externality consistent with positive equilibrium investment $(\lambda>b / 1+b)$, the level of the prohibitive trade cost is

$$
t_{p}^{C A}\left(\lambda=\frac{b}{1+b}\right)=\frac{(1-c) k(1-b)(2+b)}{k\left(2-b^{2}\right)} .
$$

It is straightforward to show that $t_{p}^{E D}<t_{p}^{C A}(\lambda=b / 1+b)$ whatever $b>0$. Hence $t_{p}^{E D}<t_{p}^{C A}$ for $\frac{b}{1+b} \leq \lambda<1$.

\section{Proof of Proposition 5:}

The sign of $d C S / d \lambda$ depends on $d \bar{x} / d \lambda$ and $d \Delta / d \lambda$ (see (18)). Using the equilibrium quantities, we have $\Delta=\frac{t k}{D}$, where $D=(1-b)(2+b) k-(2 \lambda-$ 
1) $(\lambda(1+b)-b)$, so that

$$
\frac{d \Delta}{d \lambda}=\frac{t k[4 \lambda(1+b)-(3 b+1)]}{D^{2}}
$$

The sign of $\frac{d \Delta}{d \lambda}$ depends on $\lambda$, at least as long as $t \neq 0$. A sufficient condition for $\frac{d \Delta}{d \lambda}>0$ is $\lambda>\frac{3 b+1}{4(1+b)}$. Similarly, $\bar{x}=\frac{k[2(1-c)-t]}{2 E}$, where $E=2[k(1+b)(2-$ b) $-(\lambda(1+b)-b)]$, so that

$$
\frac{d \bar{x}}{d \lambda}=\frac{k(1+b)[2(1-c)-t]}{2 E^{2}}
$$

where $\frac{d \bar{x}}{d \lambda}>0$ for $t<2(1-c)$ and $\frac{d \bar{x}}{d \lambda}<0$ for $2(1-c)<t<t_{p}^{C A}$.

In free trade, (18) reduces to

$$
\frac{d C S}{d \lambda}=-2 \bar{x} \frac{\partial p_{h}}{\partial \bar{x}} \frac{d \bar{x}}{d \lambda}
$$

This expression is unambiguously positive since $\frac{\partial p_{h}}{\partial \bar{x}}<0$ and $\frac{d \bar{x}}{d \lambda}>0$ for $t<2(1-c)$.

Consider now $0<t<t_{p}^{E D}$. Since $\frac{d \bar{x}}{d \lambda}>0$ when $t<2(1-c)$, $\frac{d \bar{x}}{d \lambda}>0$ when $0<t<t_{p}^{E D}$ provided that $t_{p}^{E D}<2(1-c)$. This is the case whenever $\lambda>\left[b+\left(\frac{2(1-b)^{2}}{2+b(1-b)}\right)^{1 / 2}\right] \frac{1}{1+b}$ and thus whenever the externality is not too strong. If this condition holds, $\frac{d C S}{d \lambda}>0$ for $0<t<t_{p}^{E D}$ unless $\frac{d \Delta}{d \lambda}>0$ is positive and strong. The presence of highly differentiated products makes sure the second part of (18) does not affect the sign of $\frac{d C S}{d \lambda}$.

\section{Proof of Proposition 6:}

To show this proposition, we must show that, when the domestic manufacturer has ED, the prohibitive trade cost is the same whether the two foreign manufacturers have CA or ED.

Consider the profit of a foreign manufacturer when it sells its product through common agencies with the other foreign manufacturer. Its profit takes the form

$$
\pi_{f}^{E D, C A, C A}=\frac{n^{2}(t) R(\lambda)}{d^{2}(\lambda)},
$$

where $n(t)=t\left[(1+b)(1-2 k)+2 k b^{2}\right]+(1-c)\left(-1-b+2 k+k b-3 k b^{2}\right)$, $R(\lambda)=k\left[2 k\left(1-b^{2}\right)(1+2 b)+(1+2 b)\left(2 b \lambda-\lambda^{2}(1+2 b)\right)-b^{2}\right]$ and $d(\lambda)=k^{2}\left(12 b^{3}+\right.$ $\left.2 b^{2}-10 b-4\right)+k\left(-4 b^{3} \lambda+b^{3}+2 b^{2} \lambda+6 b \lambda+3 b+2 \lambda+2\right)+b^{2}-2 \lambda b^{2}+b-3 \lambda b-\lambda$. 
When all the manufacturers have ED, the foreign manufacturer's profit takes the form

$$
\pi_{f}^{E D, E D, E D}=\frac{n^{2}(t) R(\lambda=1)}{d^{2}(\lambda=1)} .
$$

It follows that $t$ such that $\pi_{f}^{E D, E D, E D}=0$ and $\pi_{f}^{E D, C A, C A}=0$ takes the same value that we denote $t_{p}^{E D}$.

When the domestic manufacturer shares common retailers with one or with both foreign manufacturers, the volume of trade and the wholesale price can no longer be written as a function of $n(t) / d(\lambda)$. In these cases, the prohibitive rate depends on $\lambda$ and is higher than when the domestic manufacturer selects ED.

\section{References}

[1] Bernheim, Douglas and Michael Whinston (1998), "Exclusive Dealing", Journal of Political Economy 106, 64-103.

[2] Besanko, David and Martin Perry (1993), "Equilibrium Incentives for Exclusive Dealing in a Differentiated Products Oligopoly", RAND Journal of Economics 24, 646-67.

[3] Comanor, William S. and H.E. Frech (1985), "The Competitive Effects of Vertical Agreements?", American Economic Review, 75, 539-46.

[4] Fargeix, André and Jeffrey M. Perloff (1989), "The Effects of Tariffs in Markets with Vertical Restraints", Journal of International Economics $26,99-117$

[5] Gal-Or, Esther (1991), "A Common Agency with Incomplete Information", RAND Journal of Economics 22, 274-86.

[6] Grossman, Gene and Elhanan Helpman (2001), "Integration versus Outsourcing in Industry Equilibrium", Quarterly Journal of Economics 117, 85-120.

[7] Martimort, David (1996), "Exclusive Dealing, Common Agency and Multiprincipals Incentive Theory," Rand Journal of Economics 27, 1-31. 
[8] Marvel, Howard (1982), "Exclusive Dealing", Journal of Law and Economics $25,1-25$.

[9] Mathewson, Frank and Ralph Winter (1987), "The Competitive Effects of Vertical Agreements: Comment", American Economic Review 77, 1057-62.

[10] Monti, Mario (2000), "Who will be in the driver's seat?" Speech 00/177 at the Forum Europe Conference, Brussels, 11 May 2000.

[11] Nagaoka, Sadao and Akira Goto (1997), "Vertical Restraints and Market Access", Empirica 24, 21-36.

[12] Organisation for Economic Cooperation and Development (1999), Trade and Competition Policies for Tomorrow, Paris: OECD.

[13] Raff, Horst and Nicolas Schmitt (2002), "Endogenous Vertical Restraints in International Trade", CESifo Working Paper, No. 284.

[14] Richardson, Martin (2002), "Trade Policy and Access to Retail Distribution", Review of International Economics, forthcoming.

[15] Spencer, Barbara and Larry Qiu (2001), "Keiretsu and RelationshipSpecific Investment: A Barrier to Trade?", International Economic Review 42, 871-901.

[16] United States Department of Justice (2000), International Competition Policy Advisory Committee. Final Report, Washington, D.C.

[17] World Trade Organization (1998), Japan - Measures Affecting Consumer Photographic Film and Paper: Report of the Panel, WT/DS44/R, 31 March 1998. 


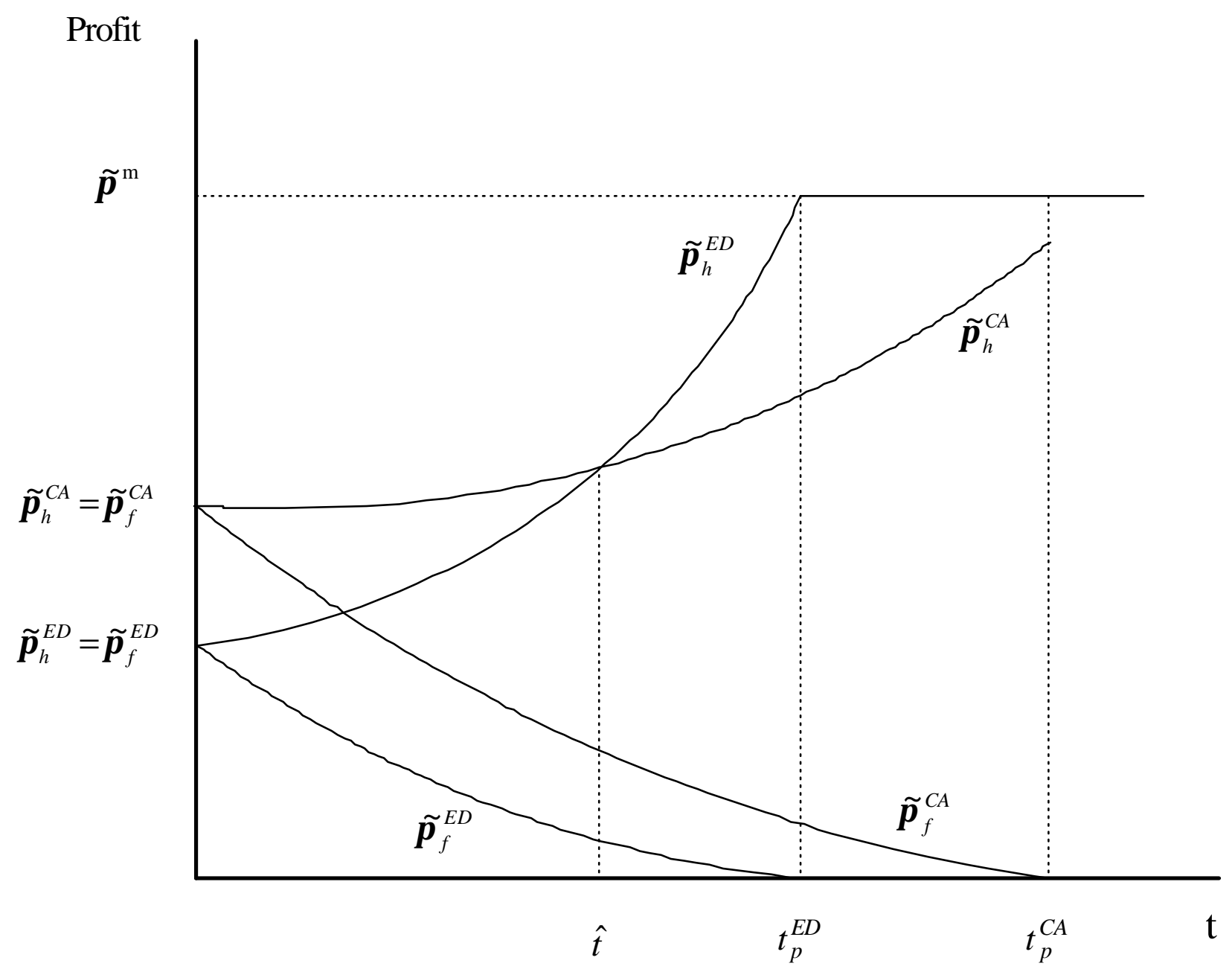

Figure 1: Exclusive Dealing vs Common Agency (low externality) 


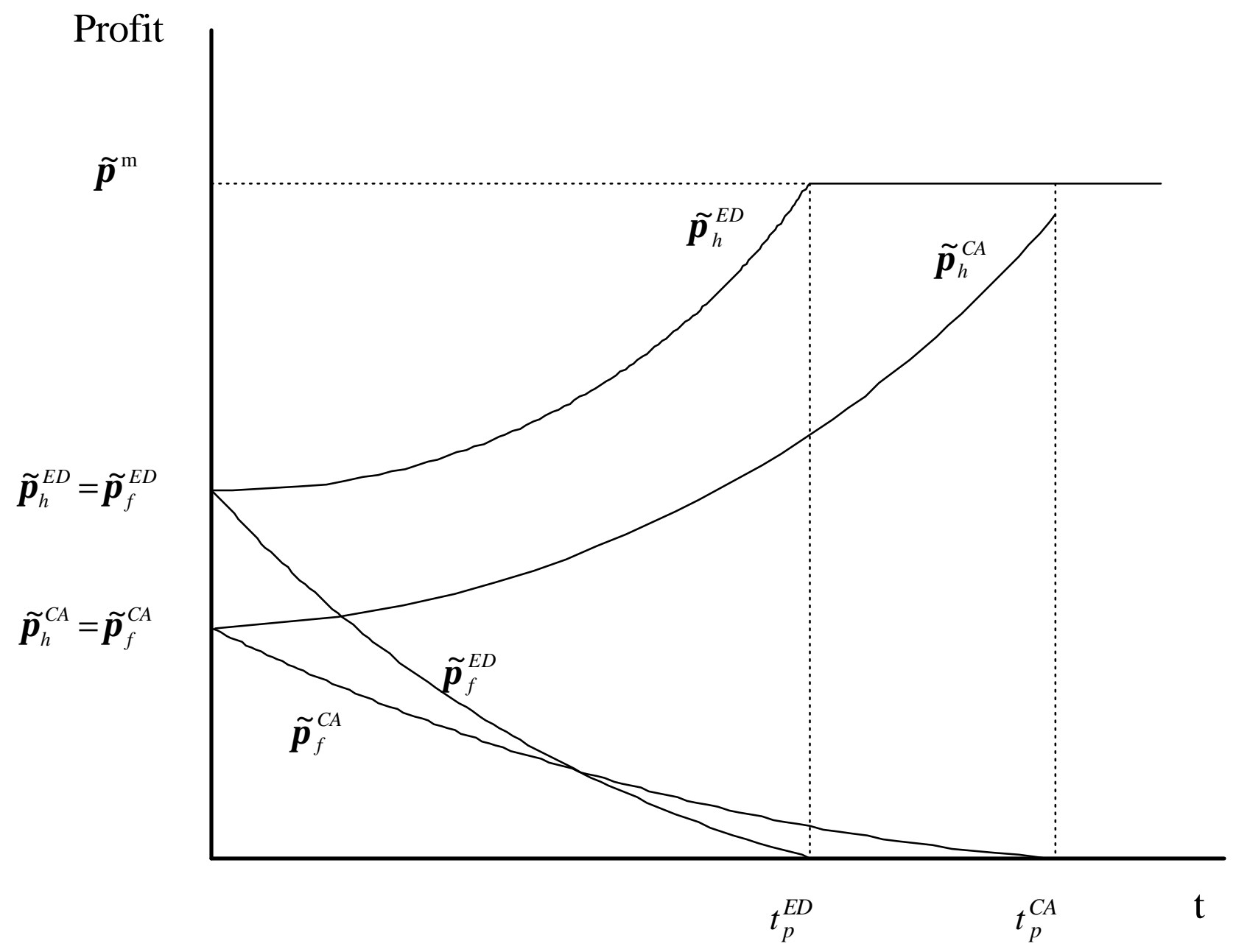

Figure 2: Exclusive Dealing vs Common Agency (high externality) 


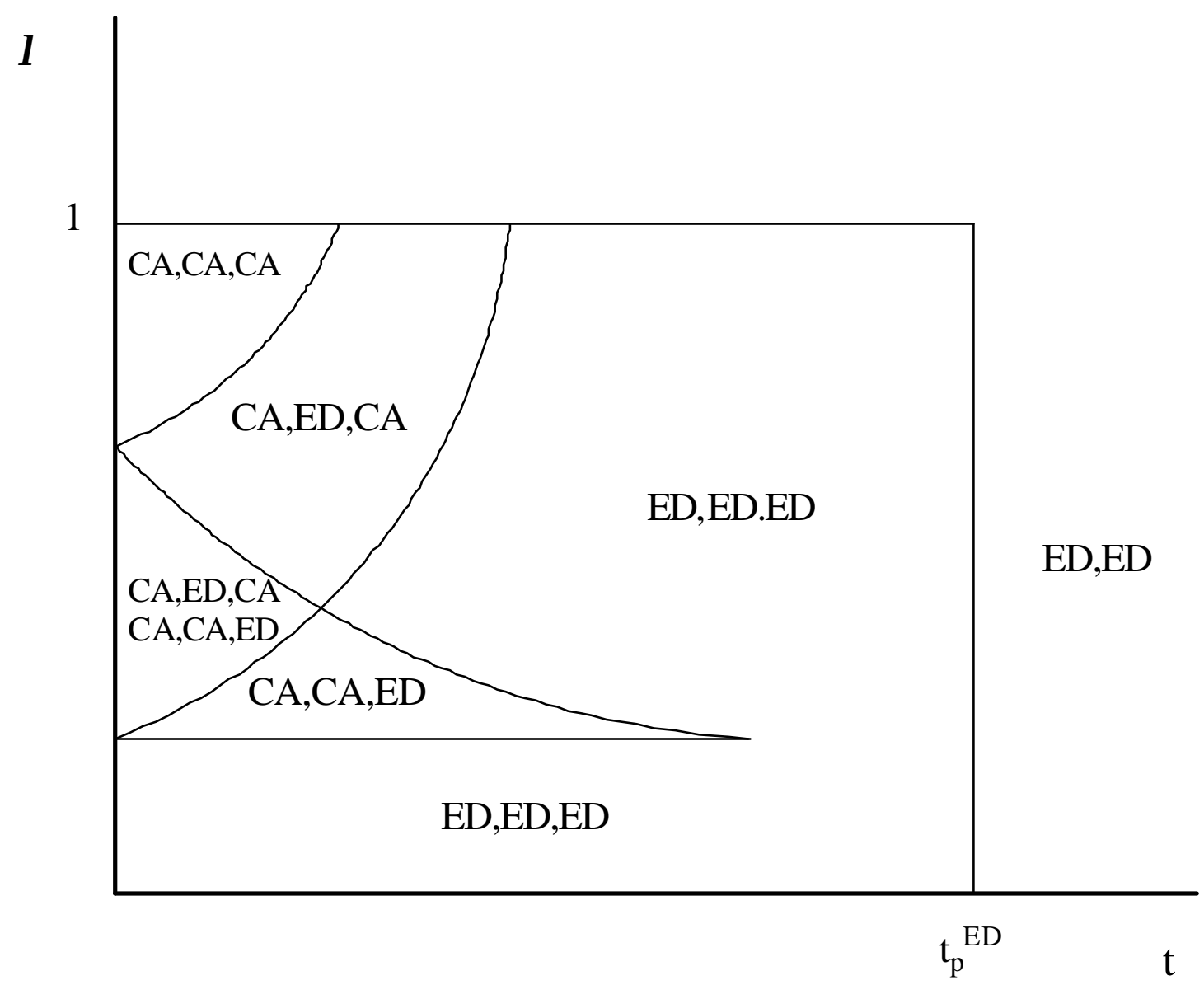

$1,2,3=\mathrm{D}, \mathrm{D}, \mathrm{F}$

Figure 3: One Foreign and Two Domestic Manufacturers 


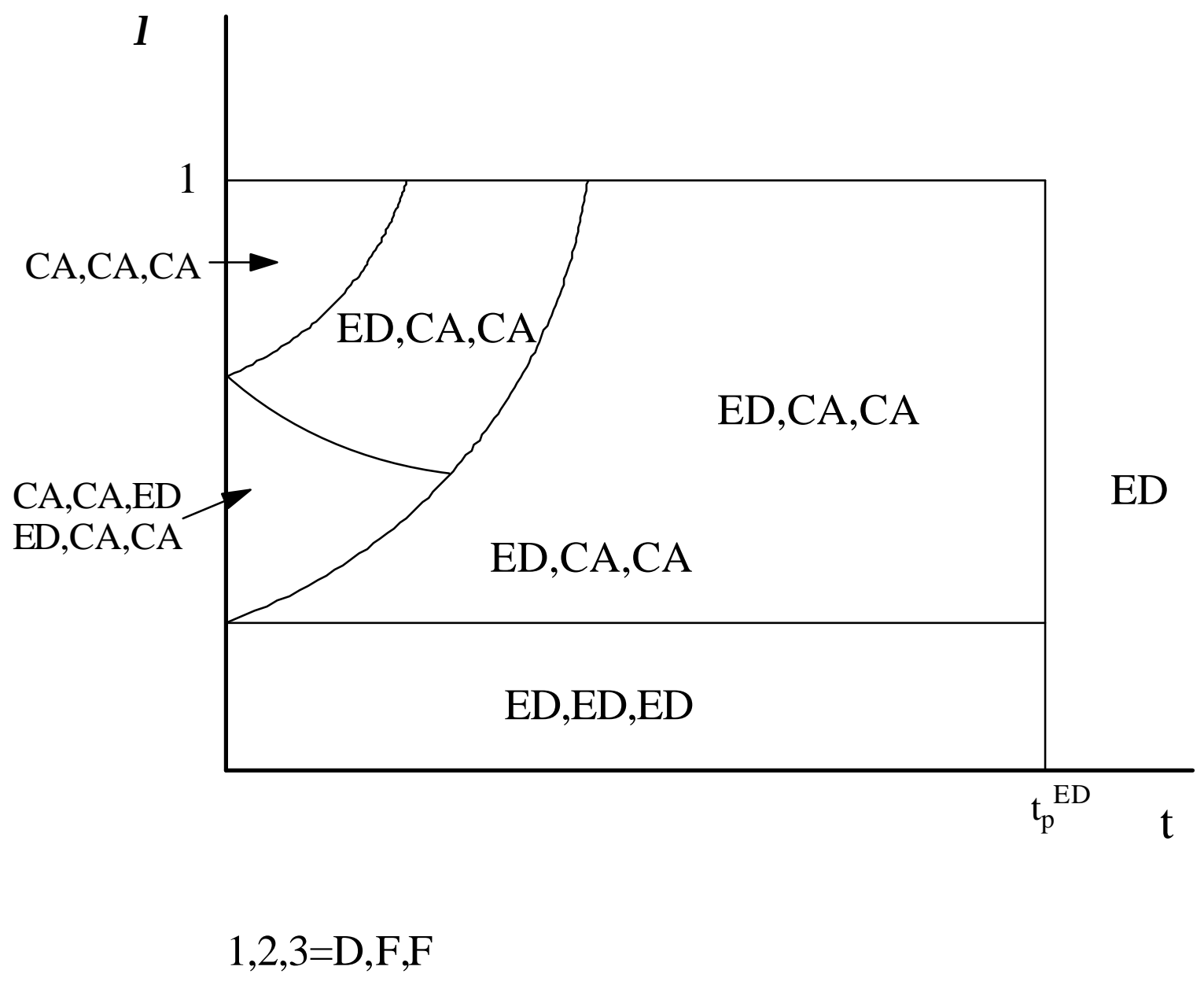

Figure 4: One Domestic and Two Foreign Manufacturers 


\section{CESifo Working Paper Series}

(for full list see www.cesifo.de)

1101 Lawrence M. Kahn, Sports League Expansion and Economic Efficiency: Monopoly Can Enhance Consumer Welfare, December 2003

1102 Laszlo Goerke and Wolfgang Eggert, Fiscal Policy, Economic Integration and Unemployment, December 2003

1103 Nzinga Broussard, Ralph Chami and Gregory D. Hess, (Why) Do Self-Employed Parents Have More Children?, December 2003

1104 Christian Schultz, Information, Polarization and Delegation in Democracy, December 2003

1105 Daniel Haile, Abdolkarim Sadrieh and Harrie A. A. Verbon, Self-Serving Dictators and Economic Growth, December 2003

1106 Panu Poutvaara and Tuomas Takalo, Candidate Quality, December 2003

1107 Peter Friedrich, Joanna Gwiazda and Chang Woon Nam, Development of Local Public Finance in Europe, December 2003

1108 Silke Uebelmesser, Harmonisation of Old-Age Security Within the European Union, December 2003

1109 Stephen Nickell, Employment and Taxes, December 2003

1110 Stephan Sauer and Jan-Egbert Sturm, Using Taylor Rules to Understand ECB Monetary Policy, December 2003

1111 Sascha O. Becker and Mathias Hoffmann, Intra-and International Risk-Sharing in the Short Run and the Long Run, December 2003

1112 George W. Evans and Seppo Honkapohja, The E-Correspondence Principle, January 2004

1113 Volker Nitsch, Have a Break, Have a ... National Currency: When Do Monetary Unions Fall Apart?, January 2004

1114 Panu Poutvaara, Educating Europe, January 2004

1115 Torsten Persson, Gerard Roland, and Guido Tabellini, How Do Electoral Rules Shape Party Structures, Government Coalitions, and Economic Policies? January 2004

1116 Florian Baumann, Volker Meier, and Martin Werding, Transferable Ageing Provisions in Individual Health Insurance Contracts, January 2004 
1117 Gianmarco I.P. Ottaviano and Giovanni Peri, The Economic Value of Cultural Diversity: Evidence from US Cities, January 2004

1118 Thorvaldur Gylfason, Monetary and Fiscal Management, Finance, and Growth, January 2004

1119 Hans Degryse and Steven Ongena, The Impact of Competition on Bank Orientation and Specialization, January 2004

1120 Piotr Wdowinski, Determinants of Country Beta Risk in Poland, January 2004

1121 Margarita Katsimi and Thomas Moutos, Inequality and Redistribution via the Public Provision of Private Goods, January 2004

1122 Martin Peitz and Patrick Waelbroeck, The Effect of Internet Piracy on CD Sales: CrossSection Evidence, January 2004

1123 Ansgar Belke and Friedrich Schneider, Privatization in Austria: Some Theoretical Reasons and First Results About the Privatization Proceeds, January 2004

1124 Chang Woon Nam and Doina Maria Radulescu, Does Debt Maturity Matter for Investment Decisions?, February 2004

1125 Tomer Blumkin and Efraim Sadka, Minimum Wage with Optimal Income Taxation, February 2004

1126 David Parker, The UK's Privatisation Experiment: The Passage of Time Permits a Sober Assessment, February 2004

1127 Henrik Christoffersen and Martin Paldam, Privatization in Denmark, 1980-2002, February 2004

1128 Gregory S. Amacher, Erkki Koskela and Markku Ollikainen, Deforestation, Production Intensity and Land Use under Insecure Property Rights, February 2004

1129 Yin-Wong Cheung, Javier Gardeazabal, and Jesús Vázquez, Exchange Rate Dynamics: Where is the Saddle Path?, February 2004

1130 Alberto Alesina and Guido Tabellini, Bureaucrats or Politicians?, February 2004

1131 Gregory S. Amacher, Erkki Koskela, and Markku Ollikainen, Socially Optimal Royalty Design and Illegal Logging under Alternative Penalty Schemes, February 2004

1132 David M. Newbery, Privatising Network Industries, February 2004

1133 Charles Yuji Horioka, The Stagnation of Household Consumption in Japan, February 2004

1134 Eiji Fujii, Exchange Rate Pass-Through in the Deflationary Japan: How Effective is the Yen's Depreciation for Fighting Deflation?, February 2004 
1135 Mark M. Spiegel and Nobuyoshi Yamori, Determinants of Voluntary Bank Disclosure: Evidence from Japanese Shinkin Banks, Febrary 2004

1136 Robert Dekle and Kenneth Kletzer, Deposit Insurance, Regulatory Forbearance and Economic Growth: Implications for the Japanese Banking Crisis, February 2004

1137 Takatoshi Ito and Kimie Harada, Bank Fragility in Japan, 1995-2003, February 2004

1138 Kunio Okina and Shigenori Shiratsuka, Policy Duration Effect under Zero Interest Rates: An Application of Wavelet Analysis, February 2004

1139 Francine D. Blau and Lawrence M. Kahn, Do Cognitive Test Scores Explain Higher U.S. Wage Inequality?, February 2004

1140 Michael Rauscher, Economic Growth and Tax-Competing Leviathans, February 2004

1141 Ernst Fehr and Jean-Robert Tyran, Money Illusion and Coordination Failure, February 2004

1142 Ingo Vogelsang, Network Utilities in the U.S. - Sector Reforms without Privatization, March 2004

1143 Marc-Andreas Muendler, Estimating Production Functions When Productivity Change is Endogenous, March 2004

1144 Sascha O. Becker, Samuel Bentolila, Ana Fernandes, and Andrea Ichino, Job Insecurity and Children's Emancipation, March 2004

1145 Pascalis Raimondos-Møller and Alan D. Woodland, Non-Preferential Trading Clubs, March 2004

1146 Robert Fenge and Matthias Wrede, EU Regional Policy: Vertical Fiscal Externalities and Matching Grants, March 2004

1147 Chi-Yung Ng and John Whalley, Geographical Extension of Free Trade Zones as Trade Liberalization: A Numerical Simulation Approach, March 2004

1148 Marc-Andreas Muendler, Trade, Technology, and Productivity: A Study of Brazilian Manufacturers, 1986-1998, March 2004

1149 Eugene Beaulieu, Vivek H. Dehejia, and Hazrat-Omar Zakhilwal, International Trade, Labour Turnover, and the Wage Premium: Testing the Bhagwati-Dehejia Hypothesis for Canada, March 2004

1150 Giorgio Brunello and Francesca Gambarotto, Agglomeration Effects on EmployerProvided Training: Evidence from the UK, March 2004

1151 S. Brock Blomberg, Gregory D. Hess, and Athanasios Orphanides, The Macroeconomic Consequences of Terrorism, March 2004 
1152 Bodo Sturm and Joachim Weimann, Unilateral Emissions Abatement: An Experiment, March 2004

1153 Wolfgang Ochel, Welfare-to-Work Experiences with Specific Work-First Programmes in Selected Countries, March 2004

1154 Jan K. Brueckner and Eric Pels, European Airline Mergers, Alliance Consolidation, and Consumer Welfare, March 2004

1155 Aaron Tornell, Frank Westermann, and Lorenza Martínez, NAFTA and Mexico's Economic Performance, March 2004

1156 George Economides, Sarantis Kalyvitis, and Apostolis Philippopoulos, Do Foreign Aid Transfers Distort Incentives and Hurt Growth? Theory and Evidence from 75 Aidrecipient Countries, March 2004

1157 Robert Fenge and Volker Meier, Are Family Allowances and Fertility-related pensions Siamese Twins?, March 2004

1158 Bruno S. Frey, Simon Luechinger, and Alois Stutzer, Valuing Public Goods: The Life Satisfation Approach, March 2004

1159 Jerome L. Stein and Guay C. Lim, Asian Crises: Theory, Evidence, Warning-Signals, March 2004

1160 Romain Ranciere, Aaron Tornell, and Frank Westermann, Crises and Growth: A ReEvaluation, March 2004

1161 Assaf Razin and Efraim Sadka, Transparency, Specialization and FDI, March 2004

1162 Ludger Woessmann, How Equal Are Educational Opportunities? Family Background and Student Achievement in Europe and the United States, March 2004

1163 B.M.S. van Praag and Barbara E. Baarsma, Using Happiness Surveys to Value Intangibles: The Case of Airport Noise, March 2004

1164 Aaron Tornell, Frank Westermann, and Lorenza Martínez, The Positive Link Between Financial Liberalization, Growth, and Crises, March 2004

1165 Helge Berger and Carsten Hefeker, One Country, One Vote? Labor Market Structure and Voting Rights in the ECB, March 2004

1166 Clemens Fuest and Martin Kolmar, A Theory of User-Fee Competition, March 2004

1167 Friedrich Schneider and Robert Klinglmair, Shadow Economies around the World: What Do We Know?, April 2004

1168 Horst Raff and Nicolas Schmitt, Exclusive Dealing and Common Agency in International Markets, April 2004 